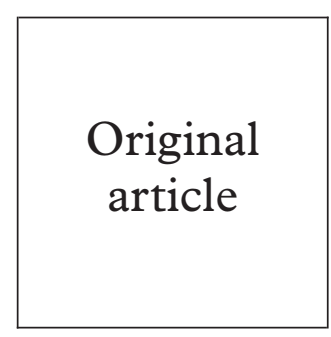

\title{
Bacterial vaginosis is not associated with circumcision status of the current male partner
}

\author{
Jonathan M Zenilman, Anne Fresia, Barbara Berger, William M McCormack
}

Objective: Bacterial vaginosis (BV) is common in sexually active women, and in a large proportion the underlying aetiology is unknown. We evaluated partner circumcision status as a potential risk and hypothesised that women with uncircumcised partners were at increased risk for BV.

Methods: Retrospective audit of a partner study (272 heterosexual couples) conducted in Baltimore between 1990 and 1992. BV defined by clinical criteria and circumcision status of males was determined by physical examination.

Results: BV was diagnosed in 83 (30\%) female partners; 75 (27\%) males were uncircumcised. In males and females respectively, gonorrhoea was diagnosed in $20 \%$ and $16 \%$, and chlamydia in $7 \%$ and $11 \%$. In women with circumcised partners, 58/197 (29\%) had BV compared with 25/75 $(33 \%)$ with uncircumcised partners $(\mathrm{p}=0.53)$.

Conclusion: Women with uncircumcised current partners are not at increased risk for BV.

(Sex Transm Inf 1999;75:347-348)

Keywords: bacterial vaginosis; circumcision

\section{Introduction}

Bacterial vaginosis (BV) is a common ecological disorder of the vaginal microflora. ${ }^{1} \mathrm{BV}$ is associated with increased risk of amniotic infection and preterm delivery, postoperative infections, and has been recently implicated as a potential cofactor in HIV transmission. ${ }^{2} \mathrm{BV}$ has been associated with presence of other STDs, douching, and use of antimicrobial agents. BV has been associated with sexual partner variables such as increased number of partners, a new sexual partner, or a male partner with urethritis. ${ }^{3}$ Careful bacteriological studies comparing circumcised and uncircumcised males in Israel found that uncircumcised males had higher proportions of Gram negative rods in the subpreputial space which was also associated with increased risk of urinary tract infections. ${ }^{4}$ Since the aetiology of BV is unknown, we proposed that the presence of an uncircumcised current male partner and the potential for infection with subpreputial organisms may increase the risk of BV.

Medicine, New York

Hospital/Cornell

Medical Center at

Queens, Flushing, NY,

USA

B Berger

Division of Infectious

Diseases, State

University of New York

Health Science Center

at Brooklyn, Brooklyn,

NY, USA

W M McCormack

Correspondence to:

Jonathan M Zenilman, MD,

Division of Infectious

Diseases, Johns Hopkins

University School of

Medicine, Ross 1159, 720

Rutland Avenue, Baltimore,

MD 21205, USA.

Accepted for publication

18 June 1999

This paper is based on a retrospective audit of data collected during a large study of STD

Table 1 Reproductive behaviours and STDs: associations with BV transmission in Baltimore conducted in $1990-2^{56}$ which included both members of 274 heterosexual partnerships. After informed consent, patients had an extensive demographic and behavioural questionnaire administered by study clinicians and physical examinations.

Laboratory evaluations included cultures for Neisseria gonorrhoeae, Chlamydia trachomatis, Trichomonas vaginalis, and a serological test for syphilis. All men had a urethral Gram stain, and non-gonococcal urethritis was defined as $>5$ white blood cells (WBC)/high power field (hpf). In the women, a vaginal fluid wet mount preparation was evaluated microscopically, and $\mathrm{pH}$ was determined. We defined $\mathrm{BV}$ using the Amsel clinical criteria ${ }^{7}$ : the presence of at least three of homogeneous discharge, $\mathrm{pH}>4.5$, clue cells $>20 \%$, or a positive amine (whiff) test. Circumcision status was determined by the examining clinician by direct visualisation. Statistical analysis were performed using PCSAS (SAS institute, Cary, NC, USA). Univariate analyses by $\chi^{2}$ and Fisher's exact test determined associations between BV and demographic, contraceptive use, douching, and STD diagnosis variables.

\begin{tabular}{|c|c|c|c|c|}
\hline & $\begin{array}{l}\text { Presence of } B V \text { in } \\
\text { people with risk }\end{array}$ & $\begin{array}{l}\text { Presence of BV in } \\
\text { people w/o risk }\end{array}$ & $O R(95 \% C I)$ & $p$ Value \\
\hline Oral contraceptive use & $13 / 56(23 \%)$ & $70 / 216(32 \%)$ & $0.63(0.3-1.31)$ & 0.18 \\
\hline $100 \%$ condom use & $16 / 73(22 \%)$ & $67 / 199(34 \%)$ & $0.55(0.28-1.08)$ & 0.06 \\
\hline Douching in past month & $68 / 201(34 \%)$ & $15 / 73(21 \%)$ & $1.98(1.00-3.94)$ & 0.03 \\
\hline Uncircumcised & $13 / 56(23 \%)$ & $70 / 216(32 \%)$ & $0.63(0.3-1.31)$ & 0.18 \\
\hline African-American & $81 / 248(33 \%)$ & $2 / 26(8 \%)$ & $5.82(1.29-36.6)$ & 0.02 \\
\hline Current smoker & $15 / 41(37 \%)$ & $48 / 141(34 \%)$ & $1.12(0.51-2.44)$ & 0.76 \\
\hline Gonorrhoea & $23 / 43(45 \%)$ & $60 / 231(26 \%)$ & $3.28(1.60-6.74)$ & $<0.01$ \\
\hline Chlamydia & $11 / 30(36 \%)$ & $72 / 244(30 \%)$ & $1.38(0.58-3.25)$ & 0.65 \\
\hline Syphilis & $7 / 12(58 \%)$ & $76 / 262(29 \%)$ & $3.43(0.94-14.1)$ & 0.05 \\
\hline Trichomonas & $31 / 58(53 \%)$ & $51 / 213(24 \%)$ & 3.65 (1.91-6.98) & $<0.01$ \\
\hline \multicolumn{5}{|l|}{ STD diagnosis in partner: } \\
\hline Gonorrhoea & $25 / 45(45 \%)$ & $58 / 219(26 \%)$ & $2.31(12.0-4.45)$ & $<0.01$ \\
\hline Chlamydia & $9 / 18(50 \%)$ & $74 / 182(29 \%)$ & $2.46(0 / 86-7.08)$ & 0.06 \\
\hline Syphilis & $5 / 9(56 \%)$ & $78 / 265(29 \%)$ & $3.00(0.68-13.7)$ & 0.13 \\
\hline Non-chlamydial non-gonococcal urethritis & $19 / 66(29 \%)$ & $59 / 197(29 \%)$ & $0.9(0.47-1.74)$ & 0.56 \\
\hline
\end{tabular}




\section{Results}

In all, 274 partnerships were evaluated in a predominantly African-American population. BV was diagnosed in $83(30.3 \%)$ women. Women with BV were older than those without (mean age 27.3 compared with 25.2 , $\mathrm{t}=0.03$ ), and had more sexual partners (mean 21.2 lifetime compared with 12.6 lifetime, $\mathrm{t}=0.09)$. BV was strongly associated with African-American race, douching in past 30 days, and a diagnosis of gonorrhoea, trichomoniasis, or syphilis (table 1).

Of the male partners, $75(27.6 \%)$ were uncircumcised. Uncircumcised men were older (mean age 28.2 compared with $24.3, \mathrm{~T}<0.001$ ) and were similar to circumcised men in racial characteristics and presence of other STDs. BV in the woman was not associated with circumcision status of her current male partner (table 1). BV was associated with a diagnosis of gonorrhoea and chlamydia in the male partner, but not with a diagnosis of syphilis or nonchlamydial non-gonococcal urethritis.

\section{Discussion}

As expected, BV was highly associated with douching and concurrent STDs, especially the presence of gonorrhoea. We found that circumcision status of the male partner was not associated with the presence of BV. BV was associated with other STDs, although BV in this context probably occurs as a secondary result of the inflammation induced by the STD, which is similar to findings reported previously in the literature. For example, previous studies by Holst in Sweden ${ }^{8}$ and Avonts et al in Belgium $^{9}$ strongly suggested $\mathrm{BV}$ was not directly caused by a sexually transmitted pathogen.

BV was statistically associated with gonococcal infection in either partner. There was no association between BV and chlamydial infection in the female partner. In contrast, when chlamydial infection was diagnosed in the male partner, there was a trend towards association with $\mathrm{BV}$ in the female $(\mathrm{p}=0.06)$. One potential explanation for these observations is organism load and infectious inoculum. In this study, which was conducted in 1990-2, chlamydia were ascertained by culture. Sensitivity of culture in men has been demonstrated to be relatively low compared with new nucleic acid amplification techniques. We speculate that the sensitivity of chlamydia testing was biased towards those men who had infectious inocula and were able to induce an infection in a female partner, resulting in cervical inflammation and a secondary BV. The conflicting chlamydia data may also be a result of small sample size since only 18 women in our sample had chlamydia positive cultures.

This study has a number of potential biases. This was a cross sectional study conducted in an African-American, urban, predominantly poor inner city STD clinic population and therefore may have limited generalisability. For example, high rates of $\mathrm{BV}$ and Gardnerella colonisation have been reported in AfricanAmerican women. ${ }^{10}$ Few longitudinal cohort studies of BV have been conducted, ${ }^{11}$ although the results suggest that $\mathrm{BV}$ is associated with sexual behaviour. Finally, we are unable to fully control for the number of sexual partners, which is a covariate for both gonorrhoea and chlamydial infection. Nevertheless, we believe that this study demonstrates that the bacteria under the foreskin of uncircumcised men do not contribute significantly to the development of bacterial vaginosis in their female partners.

Portions of this work were presented in preliminary form at the 12th meeting of the International Society for STD Research, Seville, Spain.

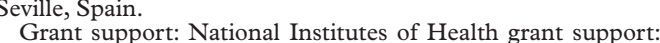
Grant support: Nati
AI34582, AI38533.

AI 34582 , AI 38533 .
The authors acknowledge the clinicians and staff of the Baltimore City Health Department STD Program for facilitating this work

Contributions: J Zenilman was principal investigator of the study, and was responsible for writing the manuscript; A Fresia was responsible for the data analysis and assembling the table and data analysis section; the idea for this study was originally developed by B Berger and W M McCormack. They participated in supervising the data analysis and in writing the manuscript.

1 Sobel JD. Vaginitis. N Engl f Med 1997;337:1896-903.

2 Sewankambo N, Gray RH, Wawer MJ, et al. HIV-1 infection associated with abnormal vaginal flora morphology and bacterial vaginosis. Lancet 1997;350:546-50.

3 Keane FE, Thomas BJ, Whitaker L, et al. An association between non-gonococcal urethritis and bacterial vaginosis and the implications for patients and their sexual partners. and the implications for patien

4 Serour F, Samra Z, Kushel Z, et al. Comparative periurethral bacteriology of circumcised and uncircum periurethral bacteriology of circumcised and

5 Zenilman JM, Smith P, Shepard M, et al. Alcohol and other substance use in STD clinic patients: relationships with STDs and prevalent HIV infection. Sex Transm Dis 1994;21:220-5.

6 Zenilman JM, Weisman CS, Rompalo AM, et al. Condom use to prevent incident STDs: the validity of self-reported condom use. Sex Transm Dis 1995;22:1-7.

7 Amsel R, Totten PA, Spiegel CA, et al. Nonspecific vaginitis. Diagnostic criteria and microbial and epidemiological associations. Am f Med 1983;74:14-21.

8 Holst E. Reservoir of four organisms associated with bacterial vaginosis suggests lack of sexual transmission. 7 Clin Microbiol 1990;28:2035-9.

9 Avonts D, Sercu M, Heyerick P, et al. Incidence of uncomplicated genital infections in women using oral contracepplicated genital infections in women using oral contracep-
tion or an intauterine device-a prospective study. Sex tion or an intauterine devi

10 Goldenberg RL, Klebanoff MA, Nugent R, et al. Bacterial colonization of the vagina during pregnancy in four ethnic groups. Am f Obstet Gynecol 1996;174:1618-21.

11 Hawes SE, Hillier SL, Benedetti J, et al. Hydrogen-peroxide producing lactobacilli and acquisition of vaginal infections. F Infect Dis 1996;174:1058-63. 